\title{
'There is death in the pot!'Exploring the agency of faith communities and the bible as an asset in addressing mycotoxin contamination of food and animal feed
}

\section{Rose Mboya ${ }^{1}$}

\begin{abstract}
This paper is an exploration of the contribution that faith communities can make towards stopping the vulnerability of poor communities to illnesses caused by the consumption of mycotoxin contaminated foods. Mycotoxins are associated with illnesses such as the dysfunction of organs and cancer. The article draws upon available literature, specifically from the author's study on home stored maize in Rungwe district, Tanzania in 2009, which revealed exceedingly high levels of mycotoxins in maize from subsistence farm households. Using the African Religious Health Assets Programme's (ARHAP) approach as a theoretical framework, the author argues for the engagement of faith communities and the Bible in stopping the consumption of mycotoxin contaminated foods.
\end{abstract}

Keywords: Faith communities'engagement, Food contamination, Poor communities' well-being, Awareness.

\section{Introduction}

Mycotoxins are toxic chemical compounds produced as by-products of metabolic activities of toxigenic fungi, and are harmful to both humans and animals (Bennet and Klich 2003: 498). Mycotoxin contamination of food products is a worldwide concern (Wild and Gong 2010: 71). So far more than 300 types of mycotoxins are known to exist, out of which 20 types occur in foods and feeds \{Institute of Food Science and Technology (IFST), 2009 \}. Epidemics caused by mycotoxins were acknowledged as early as in the 1880's in Europe. The epidemics were associated with the death of thousands of people (Smith and Moss 1985 as cited by J.I. Pitt 2000: 184). Maize, a staple food crop in Africa (M'mboyi et al 2010: 8), easily succumb to pests (Makate 2010: 3; Pitt 2000: 185), which fungal infections are part of. Favourable conditions for the development and growth of fungi include moisture and temperatures between $20-38{ }^{\circ} \mathrm{C}$ (Bennet and Klich 2003: 498. With current global warming, fungal infection of food crops may increse in places which were originaly too cold to allow for the development of fungi, thus mycotoxin contamination of food crops could also occur in such places.

$1 \mathrm{PhD}$, Food Security, School of Agricultural, Earth and Environmental Sciences, University of KwaZulu-Natal, Carbis Road, Pietermaritzburg. Email: mujilarose@yahoo.com 
In order to overcome challenges that are associated with myctoxin contamination, it is imperative that consumers of agraicultural products be well informed regarding the dangers of mycotoxin contamination. health problems that mycotoxins may cause or encourage include cancer of the eusophagus, kidney problems, interference with neurones function, interference with protein synthesis (Pitt 2000: 184 - 186), retarded growth in both humans and animals, and reduced productivity (Diekman and M.L. Green 1992: 1616 - 1617; Jewers 1990: 198 - 200). Apart from causing health problems, mycotoxins may also suppress the consumers' immune system (Oliveira et al. 2006: 357). This renders the consumesrs vulnerable to attack by diseases such as malaria, tuberculosis and HIV infection in humans.

Fungi may also reduce the nutritive value of food crops (Carl Reed et al. 2007: 546). In grains, moulds may significantly reduce the fat and carbohydrate content by feeding on these nutrients. In turn this puts consumers of fungal infected crops at risk of poor nutrition, which can further render them vulnerable to diseases. Important mycotoxins that may be found in maize include T-2 toxins and fumonisns, mainly produced by Fusarium species (Akande et al. 2006: 400), aflatoxins, produced by Aspergillus species (Akande et al 2006: 399) and ochratoxins, mainly produced by Penicillium and some Aspergillus species such as Aspergillus niger (Cabañes et al. 2010: 1112).

There are international regulatory standard limits set for different types of mycotoxins in foods and feeds(Wild and Gong 2010: 71). However, in general ordinary people are not well informed concerning mycotoxins. This is possibly due to the information on mycotoxins being available on facilities such as the internet and library books, which ordinary people especially in poor communities in most parts of Africa have no access to.. Moreover, the complex nature of scientific terms often used to report on mycotoxins may also contribte to blocking people's awareness regarding mycotoxins even where information on mycotoxins is available. Thus simple language understandable by people in different contexts is required for finding effective solutions to mycotoxins in food and feed.

The religiosity of the people in Rungwe district has not yet been documented. However, having been born and grown up in Rungwe district I would estimate that at least $50 \%$ of the people in this district are adherents of a certain Christian denomination or Church group. The many Church buildings scattered all over this district including its remote areas, and the Church activities that are carried out every week in these buildings supports this claim. With such Church involvement, the bible is an important asset that people in Rungwe district use or can use to enhance their lives. In this paper, I will reflect on 2 Kings 4:38-40 as a tool that faith communities can use in raising people's awareness concerning mycotoxins. The main questions which I seek to answer are as follows: 
1) Why should faith communities be involved in finding solutions to mycotoxin contamination of food and feed?

2) How relevant is the narrative in 2Kings 2: 38-42 for encouraging the agency of faith communities in finding solutions to mycotoxin contamination of food and feed?

\section{Mycotoxins in Maize in Rungwe District, Tanzania}

In 2009 I conducted a study on the quality of stored maize randomly collected from farm households in one of the wards in Rungwe district, Tanzania for my PHD. The study involved detecting toxigenic fungi and the mycotoxins associated with them using Elisa kits. The study revealed the presence of Fusarium, Aspergillus and Penicillium species in the maize (Mboya 2011: 185 - 260), and that people used fungal infected maize for human and livestock consumption purposes. About $86 \%$ of the 130 maize samples studied were infected by one, two or three types of the indicated fungi species. $88 \%$ of the maize samples tested for mycotoxins were contaminated by one, two or three of the following mycotoxins: fumonisins, aflatoxins, ochratoxins and T-2 toxins (Mboya 2011 185). The average quantities of the indicated mycotoxins were at least ten times higher than the internationally accepted standard limits. The fact that mycotoxin contaminated food was used for consumption purposes suggests that people in the indicated place are uninformed concerning the implications of mycotoxins on health. This would put maize consumers at risk of suffering from diseases associated with the consumption of mycotoxin contaminated foods.

\section{Religious Health Assets}

This paper employs the theory of religious health assets. The understanding that ordinary people possess religious health assets that can assist in responding to illness is the basis of this theory. The ARHAP program is based on this particular understanding of religious health assets. ARHAP's approach acknowledges the seriousness of health challenges caused by epidemics such as tuberculosis, malaria and HIV/AIDS in poor communities (Cochrane 2009: 63 - 66). It emphasizes exploring and understanding both tangible and non-tangible assets that people who are most directly affected by health challenges are in possession of. These assets are to be found from the daily activities of people's lives, and they can be used in finding solutions to health challenges that people face in different contexts no matter how poor or oppressed they may be (Vester Society 2006) ${ }^{2}$. Moreover, in the ARHAP aproach there is an understanding that the more assets people have to work with and the greater these assets are, the more likely are the people to find lasting solutions to health

2 URL Document with no page numbers 
challenges faced in different contexts. The ARHAP approach and emphasis on assets is based on the understanding that assets carry value and that they can be used for greater worth than what is already realized. Collaboration between different groups of people is viewed as necessary for implementing appropriate and necessary responses to health challenges (Cochrane 2009: 71). Another important element in ARHAP's approach is the understanding that in the African worldview health is not isolated from religion and other aspects of life (ARHAP 2006: 1). Based on this understanding, interdisciplinarity is central to finding lasting solutions to health challenges.

The ARHAP approach is suitable for use in the context of this paper for a number of reasons: First and most important is that this paper's focus is on subsistence farm households in Rungwe district, which is located within Africa, where religion plays a major role in influencing people's decisions (Mbiti 1990: 1). In general, the bible plays an important role in the daily lives of many African Christians (West 1999: 9 - 10). With this in mind, the bible have capacity to offer authoritative and appropriate guidance to many people in Rungwe district regarding health issues including those around mycotoxin contamination of food and feed. Secondly, normally, most Christians own a bible, and even where people may be too poor to own a bible they can still learn from scriptures by listening to facilitators expounding scriptures, especially in what is known as contextual bible study, a formalized method of studying the bible (West 1999: 35).

In contexual bible study, the bible is read with the poor in a critical and dialogical way, and it is interpreted in such a way that it becomes informative and transformative (West 2007: 2). Third, scriptures are often written and read in the languages of the people in different contexts, which makes it possible for individuals to embrace the messages from scriptures and intergrate them in their everyday lives. Thus scriptures may be useful in raising people's awareness and in helping them to make informed decisions regarding mycotoxins ${ }^{3}$. Lastly, in 2009 farm households in Rungwe district Tanzania were poor, most of them living below the World Bank's poverty line of USD 1.25 per day per individual (Mboya 2011: 238). There is no empirical evidence to suggest that farm households' income in Rungwe district has improved. This, together with the other facts mentioned in this section suggest that like in rest of poor Christian African communities, the bible is an important resource for life in this district.

3 The importance of using the bible for transformation is most aptly captured by the work of Ujamaa Centre by Gerald O. West and Bongi Zengele, [http://www.ujamaa.ukzn.ac.za] URL Document with no page numbers 


\section{The Link Between Poverty and the Consumption of Mycotoxin Contaminated Food}

Inadequate storage technologies that allow the presence of insect pests and dirt in maize as well as high moisture content of grain prior to storage have been found to encourage fungal infection in storage (Reed et al. 2007: 455 457). The tendency by small scale farmers in Africa to use inadequate grain storage methods has been acknowledged (Tefera et al. 2011: 2250). This tendency is often motivated by the familiarity of the storage methods to the farmers and the storage methods being cheap to construct or easy to manage (Mboya 2011: 161). Poverty, especially food scarcity has been identified as a barrier to stopping the consumption of mycotoxin contaminated food (Gallant 2012) ${ }^{4}$ because it leaves the poor with no alternative but to consume whatever food is available to them. In the light of this, poverty and mycotoxin contamination of stored maize are linked. This further implies that people and livestock in poor communities are more at risk of consuming mycotoxin contaminated foods and feeds, respectively, than those in rich communities. People can also be exposed to mycotoxins through consuming mycotoxin contaminated animal and poultry products such as meat, milk and eggs.

\section{The Role of Climate Change on Mycotoxin Contamination of Food Crops}

One of the predictions associated with climate change is that many infectious diseases new to specific places would be introduced and spread in the areas (Patz et al. 1996: 217 - 223). In Rungwe district, the increasing malaria cases, a phenomenon traditionally not common in this district, has been associated with the rise in temperature (Mwakyembe 2011) ${ }^{5}$. In this study, it is argued that with global warming, fungal infections of foods and feeds are likely to be introduced or increase in this district. This argument is partly based on the fact that I grew up in Rungwe district, and that to the best of my knowledge farmers' experiences of losing maize harvests to fungal infections is a new phenomenon. The main argument here is that a few decades ago temperatures in this district were lower and less favourable for the development and growth of moulds (Mboya and Kolanisi 2014: 25 $26,29)$. With this in mind, I do believe that people in other rural places where climatic conditions have changed or are changing in the same way as in Rungwe distinct may be facing the same problems where fungal infection of food crops is concerned. Thus people need to be informed about this. However, more research is required to ascertain the validity of this claim. 


\section{The Basis for the Engagement of Faith Communities in Stopping the Consumption of Mycotoxin Contamination of Food/Feed}

Two theological themes, namely, God's preferential option for the poor and Life abundance through Christ are relevant in this article. In this article, poverty is a state whereby people struggle to have wholeness of life in different contexts, thus negatively affecting well-being and the enjoyment of life. People who are faced with the indicated struggle are the poor. Abundant life (John 10:10) is God's will for all creation. God demonstrates this by deliberately siding with the poor to end their struggles. God's solidarity with the Israelites to liberate them from slavery in Egypt is one among several instances that demonstrate what is theologically known as God's preferential option for the poor. Like its Master, the Church has a responsibility to respond o challenges and needs that hinder human beings and all creation from having abundant life (Bass 2008: 31 - 32). Preferential option for the poor is thus a call for the Church to understand the predicament of those who are struggling to survive and deliberately join them in their struggles, siding with them to end their struggles. It is a call to solidarity with those who are suffering in different contexts (Kirylo 2006: 269) in an effort to create an environment conducive to the enhancement of abundant life.

The contribution of religious institutions in sub-Saharan Africa in providing medical care is well recognized. Likewise, the involvement of faith communities in healing the sick through prayers is also common (Chitaranjan and Radhakrishnan 2009: 247 - 253). The engagement of faith communities in providing medical care and offering prayers for the sick implies that faith communities are concerned with promoting well being. Likewise, the many documented theological debates against HIV and on factors that promote it such as poverty and the unequal power and gender relations provide evidence to the contribution that theologians are making towards promoting well-being. In this paper, the low income community in Rungwe district is faced with the contamination of maize, a staple food crop, with mycotoxins. Mycotoxins have negative implications on health and can be fatal, thus, are components of the underlying factors that frustrate the efforts to achieve the desired well being. Thus the participation of people, organizations and institutions that are involved in promoting well being is vital for ensuring that mycotoxin contamination of food/feed is stopped. Furthermore, faith communities are within the poor communities. The fact that poverty is linked with mycotoxin contamination of food/feed implies that people who are mostly affected by mycotoxins are within reach by faith communities. This further implies that faith communities are key to helping poor communities to engage in finding ways to participate in preventing or stopping mycotoxin contamination of food/feed. 


\section{Reflection on 2 Kings4:38-40 Narrative}

In the narrative in 2 Kings 4:38-40, the prophet Elisha visited a community of the sons of prophets in Gilgal at the time when there was famine in the land. This famine is said to have continued for seven years (Murray 2012) The events in the 2 Kings 4:38-40 took place sometime during Elisha's life in the second half of the 9th Century before Christ (Cline 2012). Elisha commanded his servants to cook stew for the sons of prophets. One of Elisha's servants went into the fields to collect herbs to add to the stew, and collected gourds from a wild vine too, unknown to him, and added them to the stew. While the sons of prophets were eating the stew, they realized that the stew was deadly, thus, they raised their voices saying: 'O man of God, there is death in the pot!' and they stopped eating the stew. In response, Elisha asked for flour from the sons of prophets and threw it into the stew, and the stew became safe for consumption. In this narrative, no one is reported to have died as a result of consuming the poisonous stew.

Four things are evident in the 2 Kings 4:38-40 narrative: First, there was food scarcity, therefore people were likely to cook and eat whatever looked edible. Consequently, people were at risk of consuming foods that were unsafe for consumption, which rendered them vulnerable to illnesses and death. The fact that unknown, poisonous gourds were added to the stew supports the claims made in this section. Second, the sons of prophets were quick to realize that the stew was deadly, thus they did not only stop eating it, but they also raised their voices against the poison in the stew. Third, the solution to the poison in the stew did not come entirely from Elisha, the prophet. The community that Elisha was visiting had to provide the flour, the substance which Elisha used to neutralize the poison in the stew. Thus, using what the community was in possession of, Elisha was able to stop the stew from being poisonous, and death was prevented. In the 2 Kings 4:38-40 narrative, the toxins in the food did not result from toxigenic fungi. However, the context in which the events in this narrative occurred is somehow similar to the context in which the consumption of mycotoxin contaminated foods is most likely to occur, which as indicated in the "The Link Between Poverty and the Consumption of Mycotoxin Contaminated Food" section, is in poor communities where food scarcity is common. Thus, the narrative in 2 Kings 4:38-40 has insights that people who are struggling with poverty, such as those in Rungwe district can identify with. This narrative also has important lessons that may be helpful in addressing mycotoxin contamination of food and feed.

\section{Findings}

1. There is a link between poverty and mycotoxin contamination of food and feed (Figure 1), implying that mycotoxin contamination of food and 
feed is both a scientific and a socio-economic issue, yet faith communities are hardly involved in addressing it.

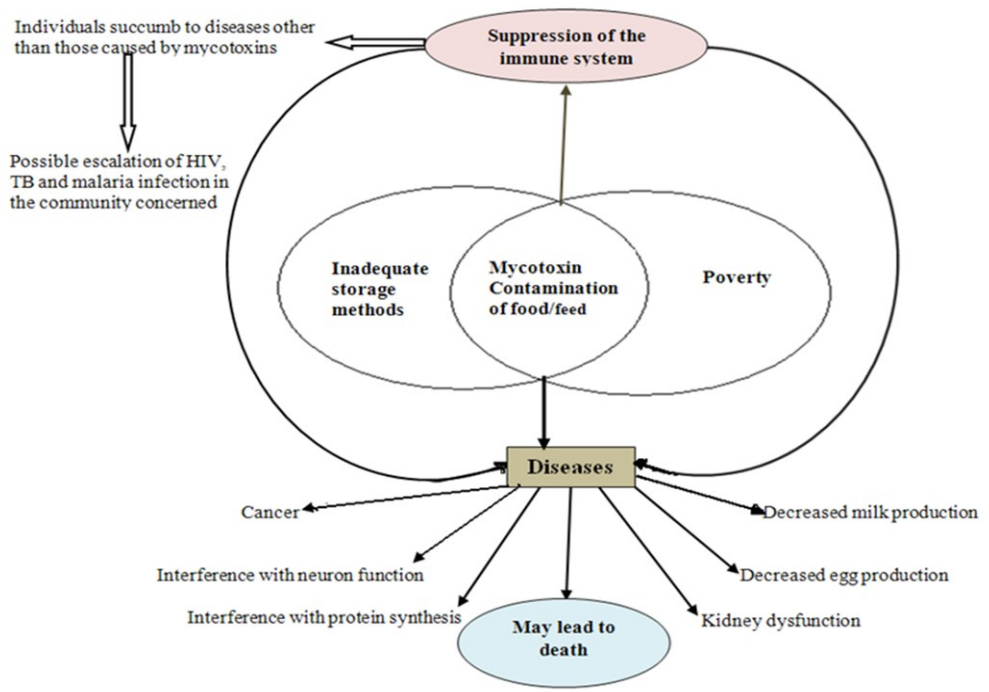

Figure 1: The link between poverty, mycotoxin contamination of food/feed and diseases

2. Food insufficiency and poverty play major roles in encouraging the consumption of unsafe food/ feed. However, while faith communities are passionate about fighting against poverty, they are silent about the latter.

3. In general, people are not well informed about mycotoxins. This puts both humans and livestock at risk of exposure to the latter, thus rendering them vulnerable to the diseases associated with the consumption of mycotoxin contaminated food/feed.

4. Scriptures, specifically the narrative in 2 Kings 4: $38-42$ has important lessons that can be helpful in raising people's awareness concerning mycotoxins among poor communities such as the subsistence farmers in Rungwe district, Tanzania.

\section{Discussion}

\section{The Implications of the Link Between Poverty and Mycotoxin Contamination of Food/feed}

The fact that mycotoxin contamination of food and feed is both a scientific and a socio-economic problem implies that solutions to it require the integration of both scientific and socio-economic approaches. Thus for mycotoxin contamination of food/feed to be addressed effectively, it could 
be helpful if scientists and people who specialize in disciplines other than science could work together against it.

The elimination of poverty in poor communities could help farmers in these communities to opt for the use of more adequate storage methods regardless of being expensive to construct. This could further help to minimize the extent of mycotoxin contamination in food/feed in the poor communities; the reduction in diseases and deaths would be outcomes. This further implies that the prevention of the escalation of HIV, Tuberculosis and malaria mentioned in Figure 1 could also be an outcome. However, the elimination of poverty in poor communities is a long term non guaranteed factor. Therefore communities that are struggling with mycotoxin contamination of staples must use all assets that are available to them to ensure safety of food regardless of their poor status. Generally speaking, governments and non government organizations (NGOs) that are involved in the development of communities will do well to prioritize the issue of finding solutions to mycotoxin contamination of food/feed.

\section{Food Scarcity, Poverty and the Consumption of Unsafe Food}

The understanding that people in poor communities, especially where poverty presents itself in the form of food scarcity, are at risk of consuming food which is not safe for consumption is also depicted in scriptures, particularly in the narrative in 2 Kings 4:30-40 (Section 2.1), where Elisha's servant collected wild, poisonous, unknown gourds and added them to the stew. Considering the fact that there was famine in Gilgal at that time, Elisha's servant possibly added the poisonous gourds to the stew to increase its quantity or its nutritive value or both. The events in this narrative alsoimply that food scarcity/poverty may lead people to be incautious regarding the safety of food that they consume. Thus finding lasting solutions to food scarcity is crucial for stopping the consumption of foods that are unsafe for consumption, such as mycotoxin contaminated food. As also depicted in the 2 Kings 4:30-40 narrative, lasting solutions to the consumption of mycotoxin contaminated food may not come entirely from governments or NGOs. Instead, the involvement of the people or communities that are struggling with mycotoxin contamination of food/feed may be required. In the 2 Kings 4:30-40 narrative, Elisha uses flour, a substance that the people he was dealing with were in possession of, and used it to heal the food. Elisha's use of flour, obtained from the same community to cure the poisonous stew may mean that within the communities struggling with mycotoxin contamination of food/feed, there is a possibility of finding materials that can lead to lasting solutions to the indicated challenge. 
In principle, what Elisha did is similar to what ARHAP and community development advocates such as Sen (1996: 190 - 203) as well as Servaes (1996: 15) recommend for effective community development or social change, that is: involving people in their own development. Making use of the capabilities of individuals, their skills and knowledge are important not only for finding lasting solutions to socio-economic problems in poor communities, but it could also help to minimize expenses. Therefore in order to find lasting solutions to mycotoxin contamination of food/feed, governments NGOs and everyone else who seeks to engage in this battle should also ask the following questions: what resources are available in poor communities, which can be used to stop the production of mycotoxins in food? How can their storage technologies be improved so that fungal infections and the subsequent mycotoxins are minimized? What materials or tools are available in these communities, which can be used to raise people's awareness regarding mycotoxins?

\section{The Importance of Raising People's Awareness Regarding Mycotoxins}

Many of the diseases caused by the consumption of mycotoxin contaminated food/feed can be prevented if the contamination of foods by mycotoxins could be stopped. However, this cannot be achieved if people are not informed about mycotoxins. In the case of Katumba ward for instance, where almost all of the farm households used fungal infected maize for consumption purposes, effort should be made to raise people's awareness concerning the negative implications of fungal infections on food/feed (Mboya and Kolanisi 2014: 25 - 26, 29). The extent to which faith communities are willing to engage in demanding governments' prioritization in relation to educating people about mycotoxins requires investigation. Likewise, whether religious institutions such as churches are willing or not willing to make available their buildings for accommodating gatherings for awareness campaigns against mycotoxin contamination of food/feed needs to be explored.

In the context of the 2 Kings 4:38-40 narrative, three things protected the community of the sons of prophets from the poison in the stew, namely: the realization that there was poison in the stew, their act of crying out, shouting or screaming to notify Elisha regarding the poison and their act of stopping to eat the stew. We are not told what exactly led to the community of the sons of prophets' realization of the poisonous state of the stew, but what is important here is that they realized that there was poison in the stew. This realization is what led them to scream at the top of their voices, making their voice heard with respect to the poison in the stew. In turn, this 
led to Elisha taking action in order to find an effective solution against the poison, and death was prevented.

Unlike the community of the sons of prophets in the 2Kings narrative, the lack of awareness of the community in Rungwe district with respect to the possible poisonous state of the infected maize lead to the indicated community to keep silent about their predicament. They neither stop consuming fungal infected maize nor take action to find lasting solutions to fungal infection of maize and the associated mycotoxins. These factors make them vulnerable to mycotoxin related diseases indicated in Figure 1. Therefore engaging in raising people's awareness regarding fungal infection and mycotoxin contamination of food is crucial for encouraging them to participate in finding the desired solutions.

\section{Conclusion}

This paper has shown that due to the capacity of mycotoxins to cause serious diseases and due to their deadly nature, lasting solutions to fungal infection and mycotoxin contamination of food are necessary. It has also been argued in this paper that finding lasting solutions to mycotoxin contamination of food and feed requires making use of scientific and sociological approaches as well as encouraging participation. Furthermore, raising people's awareness regarding mycotoxins has been shown to be necessary for encouraging participation in taking action against mycotoxin contamination of food and feed. The role of faith communities in raising peoples' awareness regarding mycotoxin contamination of food and feed has been emphasized, and the importance of the bible in relation to the latter has been affirmed.

\section{References}

Akande, K. E., Abubakar, M.M., Adegbola T.A. and Bogoro, S.E. 2006. Nutritional and Health Implications of mycotoxins in Animal Feeds: A Review. Pakistan Journal of Nutrition 5: 398-403. (Akande, Abubakar, Adegboloa and Bogoro 2006: 399 - 400).

ARHAP 2006. Appreciating Assets: The Contribution of Religion to Universal Access in Africa, Report for the World Health Organization. Cape Town: ARHAP (2006: 1).

Bass D. C. 2008, Ways of Life abundant. I Bass D.C. and Dykstra C, Eds. Practical Theology, Education and Children Ministry. Grand Rapids: Wm. B, Eerdmans Publishing co.

Bennet, J. W. and Klich. M. 2003. Mycotoxins. Clinical Microbiology Reviews 16 (3), July: 497 - 516. (Bennet and Klich 3002: 498). DOI: 10.1128/CMR.16.3.497-516.2003. 
Cabañes, F. J., Bragulat M.R. and Castella, G. 2010. Ochratoxin A Producing Species in the Genus Penicillium. Toxins 2 (5), May: 1111 - 1120. (Cabañes 2010:1112). DOI: 10.3390/toxins2051111.

Cline, A. 2012. Comment on Elisha, "Elisha, Profile and Bibliography of Elisha, Old Testament Prophet and Biblical figure. [http://atheism.about.com/old/biblepeopleoldtestament/p/Elisha.ht ml]. (Accessed July 15).

Cochrane, J. R. 2009. Religion, Public Health and a Church for the 21st Century. The International Review of Mission 95 (376 - 377), January: 59 - 72. (Cochrane 2009: 63 - 66, 71).

Diekman, M. A. and Green, M. L. 1992. Mycotoxins and Reproduction in Domestic Livestock. Journal of Animal Science 70, May: 1615 - 1627. (Diekman and Green 1992: (Diekman and Green 1992: 1616 - 1617).

Gallant, A. 2012. Helping Businesses Develop S Food Practices or Adopt Certification Standards. Comment on food safety. [http://globalfoodsafetyresource.com/article/new-content/242-food -sciencetechnology/672-mycotoxins-linked-to-malnutrition-in-deve loping-countries.html] (Accessed June 03, 2012).

Green, A., Shaw, J., Dimmock, F. and Conn, C. 2002. A Shared Mission? Changing Relationships between Government and Church Health Services in Africa. International Journal of Health Planning and Management 17, November: 333 - 353. (Green, Dimmock and Conn 2002: 336 - 339). DOI:10.1002/hpm.685.

IFST. 2009. Mycotoxins. Information Statement. [http://www.ifst.org/about_ifst/hotspot/index/29514/Updated_Myc otoxins_Information_Statement]. [Accessed March 02, 2012].

Jewers, K. 1990. Mycotoxins and their Effects on Poultry Production. CIHEAM-Option Méditerranéennes 7: 195 - 202. (Jewers 1990: 198 - 200).

Kirylo J. D. 2006. Preferential option for the poor. Making a Pedagogical Choice. Childhood Education, 82:5, 266-270. (Kirylo 2006: 269). DOI: $10.1080 / 00094056.2006 .10522839$.

Makate, N. 2010. The Susceptibility of Different Maize Varieties to Post Harvest Infestation by Sitophilus zeamais (MOTSCH) (Coleoptera:Cuclionidae). Scientific Research and Essay 5 (1), January: 030 - 034. (Makate 2010: 030).

Mbiti, J. S. 1990. African Religions and Philosophy. Oxford: Heinemann. (Mbiti 1990: 1). 
Mboya, R. 2011. A study of the Effects of Storage Methods on the Quality of maize in Rungwe District, Tanzania. Unpublished PHD Thesis, University of KwaZulu-Natal. Pietermaritzburg, South Africa. (Mboya 2011:185 - 206, 238, 161).

Mboya R. M and Kolanisi U. 2014. Subsistence Farmers' Mycotoxin Contamination Awareness in the SADC Region: Implications on Millennium Development Goal 1, 4 and 6. Journal of Human Ecology, 46(1): 21-31. (Mboya and Kolanisi 2014: 25 - 26, 29).

M'mboyi, F., Mugo, S. Mwimali, M. and Ambani, L. 2010. Maize Production and Improvement in sub-Saharan Africa. Nairobi: The African Biotechnology Stakeholders Forum (ABSF), 2010. (M'mboyi, Mugo, Mwimali and Ambani 2010: 8).

Murray, Andrew. 2012. Waiting on God. Commentary on 2 Kings 4:38-40, [http://www.studylight.org/com/mhc-com/view.cgibook=2k\&chapt er=004]. (Accessed August 04 2012).

Mwakyembe, F. 2011. Comment on Climate Change in Rungwe district, "Malaria threatens Tanzania highlands. [http://thecitizens.co.tz/sunday-citizen/-/8812-malaria-threatens-tan zanias-highlands]. (Accessed August 12, 2012).

Oliveira, G. R., Ribeiro. J.M., Fraga, M.E. Cavaglieri, L.R., G.M., Keller, K.M., Dalcero A.M. and Rosa, C.A. 2006. Mycobiota in Poultry Feeds and Natural Occurrence of Aflatoxins, Fumonisins and Zearalenone in the Rio de Janeiro State, Brazil. Mycopathologia 162 (5), November: 357. (Oliveira, Ribeiro, Fraga, Cavglieri, Keller, Dalcero and Rosa 2006: 357). DOI:10.1007/s11046-006-0070-5.

Patz, J. Paul A., Epstein, R, Burke T. A., and Balbus, J.M. 1996. Global Climate Change and Emerging Infectious Diseases. JAMA 275 (3), January: 217 - 223. (Patz, Epstein, Burke and Balbus 1996: 223). DOI:10.1001/jama.1996.03530270057032.

Pitt, J.I. 2000. Toxigenic Fungi and Mycotoxins. British Medical Bulletin 56 (1):184 - 192. (Pitt 2000: 184 - 186).

Andrade, C. and Radhakrishnan, R. 2009. Prayer and Healing: A Medical and Scientific Perspective on Randomized Controlled Trials. Indian Journal of Psychiatry 51 (4): 247 - 253 (Andrade and Radhakrishnan 2009: 247). DOI: 10.4103/0019-5545.58288.

Reed, C., Doyungan, S., Loerger B. and Getchell, A. 2007. Response of Storage Molds to Different Initial Moisture Contents of Maize (Corn) Stored at $250 \mathrm{C}$, and effect on respiration rate and nutrient 
Composition. Journal of Stored Products Research 43 (4): 443 458. (Reed, Doyungan, Loerger and Getchell 2007: 455 - 457). DOI: http://dx.doi.org/10.1016/j.jspr.2006.12.006.

Sen, A. 1996. Development as Freedom. Oxford: Oxford University Press. (Sen 1996: 190 - 203).

Servaes, J. 1996. Introduction: Participatory Communication and Research in Development Settings, in Participatory Communication for Social Change, edited by Servaes, J., Jacobson, T. L. and White, S. A., 13 - 25. New Delhi: Sage. (Servaes 1996:15).

Tefera, T., Mugo, S. and Likhayo, P. 2011. Effects of Insect Population Density and Storage time on Grain Damage and Weight Loss in Maize due to the Maize Weevil Sitophilus zeamais and the Larger grain borer Prostephanus truncates. African Journal of Agricultural Research 6 (10), May: 2247 - 2254. (Tefera, Mugo and Likhayo 2011: 2250). DOI: 10.5897/AJAR11.179.

Vesper Society 2006. Comment on Dr. Steve de Gruchy's presentation. Dr. Steve de Gruchy's Presentation on the Work of ARHAP. [http://www.vesper.org/newsletter/images_2006_03/WCC_Article. pdf]. (Accessed October 04, 2012).

West, G.O. 1999. The Academy of the poor. Towards a Dialogical Reading of the Bible. Trowbridge: Sheffield Academic Press. (West 1999: 9 - 10, 35).

West, G. O. 2007. Reading Otherwise. Socially Engaged Bible Scholars Reading with Their Local Communities. Atlanta: Society of Biblical Literature. (West 2007: 2).

Wild, C. P. and Gong, Y.Y. 2010. Mycotoxins and Human Disease; A Largely Ignored Global Health Issue. Carcinogenesis. 1 (3), January: 71 - 82. (Wild and Gong 2010: 71). DOI: 10.1093/carcin/bgp264. 